\title{
Esquizofrenia: papel-chave do Médico de Família e recurso ao internamento em regime compulsivo
}

José Eduardo Mendes, ${ }^{1}$ Ana Vaz Ferreira, ${ }^{1}$ Sofia Morais, ${ }^{2,3}$ Carolina Gil ${ }^{4}$

\begin{abstract}
RESUMO
Introdução: A esquizofrenia é uma síndroma psiquiátrica caracterizada por alterações cognitivas, comportamentais e emocionais associadas a uma marcada disfunção social. Os doentes com esta patologia não apresentam crítica face à própria doença, o que muitas vezes conduz à falta de adesão à terapêutica, condicionando descompensação e agravamento do quadro clínico. O internamento em regime compulsivo é uma ferramenta de último recurso para estas situações. Devido à dificuldade de avaliação destes doentes, muitas vezes só através de um acompanhamento de proximidade conseguido pelo médico de família é possível determinar as reais consequências da doença e desta forma permitir o início do tratamento psiquiátrico mais rápido.

Descrição do caso: Mulher de 48 anos, divorciada, desempregada, constituindo uma família unitária, com diagnóstico de esquizofrenia desde os 30 anos de idade, que recorre à consulta da sua médica de família por queixas de descompensação do quadro psiquiátrico, com ideação delirante persecutória e interpretações delirantes. Ao longo de quatro meses recorre várias vezes à consulta da sua médica de família pelos mesmos motivos, verificando-se uma deterioração progressiva do seu funcionamento global, tendo a situação evoluído até um estado de agressividade com perigo iminente para si e para os outros. Como mantinha a recusa para se submeter ao necessário tratamento médico, foi contactada a autoridade de saúde para se proceder ao internamento em regime compulsivo.

Comentário: A esquizofrenia é uma doença altamente incapacitante. Quando não controlada leva inevitavelmente a agudizações do estado clínico que são difíceis de gerir. A lei portuguesa contempla estes casos e prevê o recurso ao internamento em regime compulsivo. O médico de família tem vários recursos de saúde ao seu dispor e um conhecimento privilegiado do doente e do meio familiar que podem ser usados na gestão eficaz da deterioração psiquiátrica.
\end{abstract}

Palavras-chave: Esquizofrenia; Internamento Compulsivo de Pessoa com Doença Mental.

\section{INTRODUÇÃO}

esquizofrenia é uma doença psiquiátrica, consi-

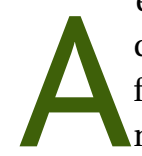
derada uma das mais severas e incapacitantes do foro psiquiátrico. ${ }^{1}$ Os doentes com esta patologia não apresentam crítica (insight) face à própria doença, o que muitas vezes conduz à falta de adesão à terapêutica e consequente descompensação e agravamento do quadro clínico. Estas descompensações, que cursam com a recrudescência de sintomas psicóticos (ideias delirantes, alucinações, alterações graves do comportamento), são muitas vezes o episódio final de uma des-

'Médico Interno de Medicina Geral e Familiar, USF Mondego, ACES Baixo Mondego ${ }^{2}$ Médica Interna de Psiquiatria, Serviço de Psiquiatria, CHUC

${ }^{3}$ Faculdade de Medicina, Universidade de Coimbra

${ }^{4}$ Médica Assistente de Medicina Geral e Familiar, USF Mondego, ACES Baixo Mondego compensação gradual. Para além disso, a esquizofrenia pode cursar com deterioração cognitiva, que se deve ao curso natural da doença, mas também aos episódios de descompensação que agravam o prognóstico da doença.

Na doença psiquiátrica, o médico de família (MF) ocupa uma posição privilegiada por ser conhecedor do doente e do seu meio familiar, o que é útil na prevenção da descompensação; no entanto, quando esta acontece este deve ser conhecedor dos recursos à sua disposição e do encaminhamento que pode ser feito. Quando a referenciação aos cuidados de saúde secundários (CSS) falha é necessária uma outra opção - o desencadear do internamento em regime compulsivo. O internamento em regime compulsivo é uma intervenção clínica de tratamento psiquiátrico de último recurso. ${ }^{2}$ Esta ferramenta 
destina-se ao doente psiquiátrico sem capacidade de autocrítica para a sua situação clínica, quando este representa um perigo para o próprio e/ou para terceiros. ${ }^{3}$

Neste artigo, os autores analisam um caso clínico e pretendem mostrar o papel fulcral do MF na gestão das descompensações psiquiátricas, servindo como um guia para o internamento em regime compulsivo accionado nos cuidados de saúde primários.

\section{DESCRIÇÃO DO CASO}

Manuela (nome fictício), mulher de 48 anos de idade, divorciada, com dois filhos, caucasiana, de nacionalidade portuguesa, natural de uma zona rural da região Centro, reside actualmente numa das freguesias da área de influência da nossa USF.

Conforme representado na linha de vida de Medalie (Quadro I), Manuela casou e teve o primeiro filho aos 18 anos e emigrou para a Suíça aos 19 anos. Lá nasceu a segunda filha em 1995. Neste ano são descritos delírios de ciúme dirigidos ao marido que terão motivado o divórcio do casal. Regressou a Portugal em 1995 e, segundo registos dos CSS, no ano seguinte foi diagnosticada com esquizofrenia. Após processo judicial foi-lhe retirado o poder paternal e a filha regressou à Suíça.

Entre os 41 e os 45 anos (2007 a 2011) registam-se quatro internamentos no pólo Hospital Sobral Cid - Centro Hospitalar e Universitário de Coimbra (CHUC), com a duração mínima de um mês e máxima de três meses, sempre por agudizações do quadro base e incumprimento da terapêutica prescrita. Desde então manteve o seguimento em consultas de psiquiatria nesse pólo hospitalar, sendo a última consulta em Outubro de 2013, após a qual abandonou o seguimento por iniciativa própria.

À data vive sozinha, constituindo uma família unitária, tendo-se afastado progressivamente ao longo dos anos de praticamente toda a família. Quando o quadro clínico agrava, com delírios persecutórios mais evidentes, refugia-se na casa dos pais, já idosos, que habitam a cerca de $30 \mathrm{~km}$ da residência actual da utente. Estes pe- ríodos são curtos, sendo o suporte parental baixo, pois o pai tem várias comorbilidades, sendo cuidador da esposa dependente para as actividades da vida diária. Manuela tem uma relação conflituosa com a irmã, que se opõe a que passe essas temporadas em casa dos pais por considerar que os sobrecarrega e por recusar o tratamento. Não tem nenhuma relação com os irmãos e sobrinhos e, por proximidade geográfica, tem contacto ocasional superficial com duas primas. Não foi possível apurar se estabelece relações de amizade.

O genograma (Figura 1) permite-nos identificar patologia psiquiátrica na família, possivelmente também esquizofrenia, no irmão mais novo.

Trata-se de uma utente grande utilizadora dos cuidados de saúde, que ao longo dos quatro primeiros meses de 2014 apresentou 10 consultas na USF, três observações no Serviço de Urgência (SU) do pólo do Hospital Geral (HG) - CHUC e uma observação no SU do pólo dos Hospitais da Universidade de Coimbra (HUC) - CHUC.

A história da doença actual referente a este episódio de agudização iniciou-se a 8 de Janeiro de 2014, quando a utente recorre à consulta da sua $\mathrm{MF}$, depois de duas idas consecutivas ao SU do HG-CHUC por queixas de "desgastes corporais e alergias mágicas" (sic) com três meses de evolução e cãibras nos membros inferiores. Nessa consulta manteve as queixas já referidas no SU, pediu 


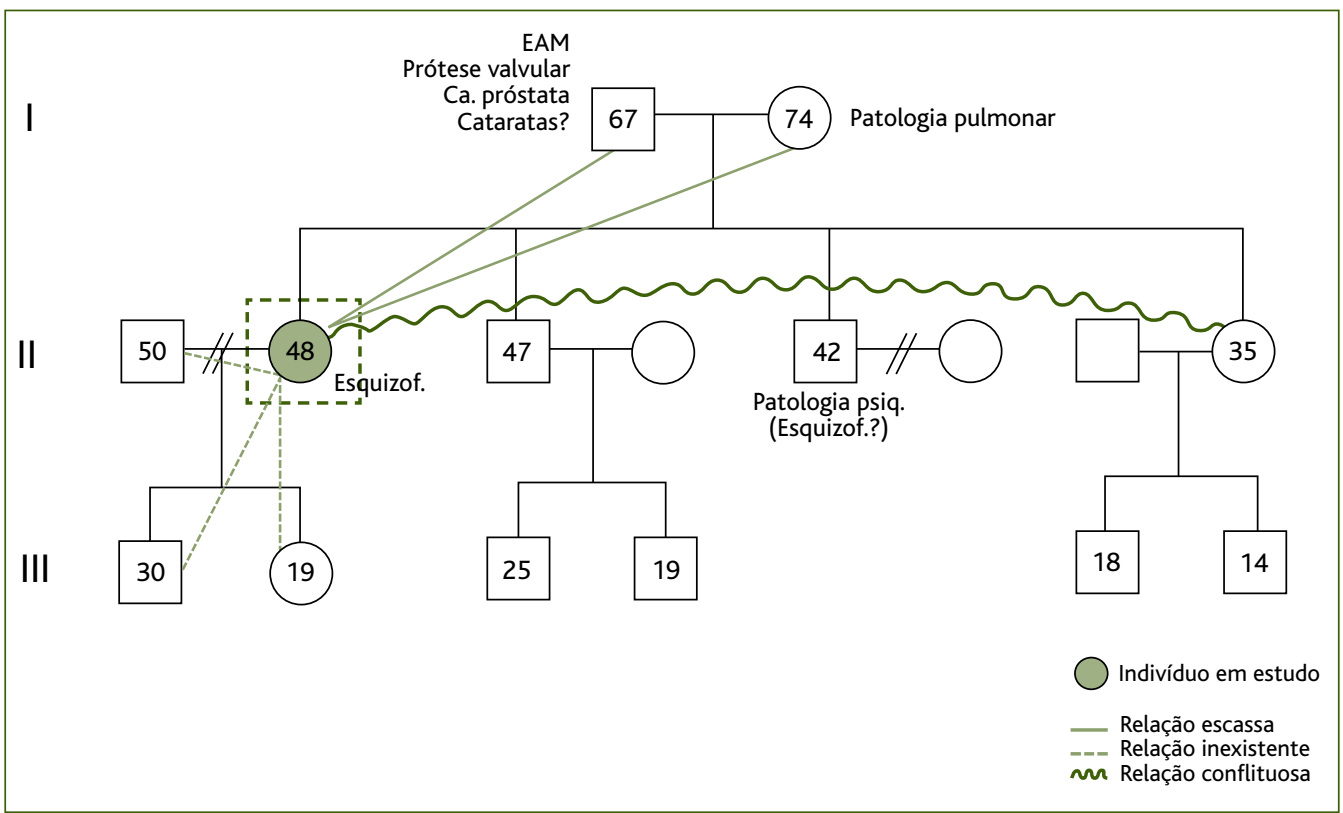

Figura 1. Genograma e psicofigura de Mitchell da utente, realizados a 16 de Maio de 2014.
Dadas as dificuldades nas referenciações para o SU/ /CSS, optou-se pela referenciação ao psiquiatra da comunidade, consulta à qual efectivamente compareceu em Março de 2014, 15 dias após a referenciação, onde se confirmou a descompensação da doença psiquiátrica, apresentando-se a utente sem crítica para a doença e sem cumprimento da medicação. Nesta consulta foi prescrito um antipsicótico oral, que a utente também não cumpriu. No início de Abril de 2014 agravou a sintomatologia prévia, com ideação delirante persecutória que condicionava o autocuidado e a higiene pessoal ["não tomo banho há três semanas porque eles apanham-me e mandam radiações e fico com o corpo pequeno em segundos" (sic)]. Refere também caminhar grandes distâncias por dia, justificando para "eles não a conseguirem sintonizar" (sic) e evidencia interpretações delirantes, pois apesar de ser observável uma abrasão na face plantar do pé esquerdo devido à marcha, a utente justifica-a dizendo "levei há pouco tempo uma chumbada no pé" (sic). Viu-se nestas repercussões físicas objectiváveis pela utente nova oportunidade dissimulada de referenciação para o SU/CSS. Manuela recorreu ao SU-HUC dias depois, por iniciativa própria, com a queixa da lesão no pé, onde foi encaminhada para observação por psiquiatria, mas novamente teve alta por abandono do SU.

A 28 de Abril de 2014, as duas primas de Manuela dirigiram-se à USF e informaram-nos que a sintomatologia se havia alterado recentemente, apresentando agora episódios de agressividade verbal dirigida a familiares e sendo-nos relatado que seria portadora de arma branca (faca) na carteira, motivos que preocupam as familiares, a quem frequentemente pede ajuda. As familiares referem frustração, desalento e angústia com esta situação. tação necessária. 
Desta forma, e por se terem esgotado todos os outros meios ao alcance do MF, optou-se pela elaboração de informação clínica para o médico de saúde pública e assim se proceder à avaliação clínico-psiquiátrica de urgência, com internamento em regime compulsivo.

A utente acaba por ser acompanhada por agentes da GNR até ao SU do CHUC-HUC, no dia 2 de Maio de 2014, onde foi avaliada por psiquiatria e objectivado quadro de delírio persecutório, ausência de crítica para a sua sintomatologia e recusa em cumprir terapêutica, com heteroagressividade dirigida a familiares e risco para si e para terceiros, ficando em observação. Nesta ida ao SU, a utente fugiu e foi reconduzida no dia seguinte, tendo-se optado pelo internamento em regime compulsivo. Esteve internada no pólo do Hospital Sobral Cid - CHUC durante mais de um mês e actualmente encontra-se no domicílio, mantendo seguimento em consultas de psiquiatria. Após a alta teve uma consulta na nossa USF, mantendo-se estável do ponto de vista psicopatológico.

\section{COMENTÁRIO}

A esquizofrenia é uma doença psiquiátrica extremamente incapacitante e é a patologia que mais motiva o recurso ao internamento compulsivo. ${ }^{4}$ Provoca a diminuição da crítica e consciência (awareness) das necessidades do próprio. A percepção da doença é essencial para a adesão terapêutica e o internamento demonstrou um aumento dessa adesão. ${ }^{5}$

Em Portugal, os cuidados de saúde mental começaram a ser integrados no Sistema Nacional de Saúde em $1985 .{ }^{6}$ Em 1998, com a criação da Lei de Saúde Mental, como expresso na Lei n. ${ }^{\circ} 36 / 98$, de 24 de Julho, fica previsto o recurso ao internamento em regime compulsivo, ou seja, o internamento por decisão judicial para doentes com mais de 14 anos de idade com anomalia psiquiátrica grave. ${ }^{3}$

O internamento em regime compulsivo tem duas modalidades: o internamento normal ou comum e o internamento de urgência. O internamento comum, esclarecido pelo artigo $12 .^{\circ}$ da Lei de Saúde Mental, destina-se ao "portador de anomalia psíquica grave que crie, por força dela, uma situação de perigo para bens jurídicos, de relevante valor, próprios ou alheios, de natureza pessoal ou patrimonial, e recuse submeter-se ao necessário tratamento médico pode ser internado em estabelecimento adequado" ou quando o doente "não possua o discernimento necessário para avaliar o sentido e alcance do con- sentimento, quando a ausência de tratamento deteriore de forma acentuada o seu estado." O internamento de urgência aplica-se "sempre que, verificando-se os pressupostos do artigo $12 .^{\circ}$, exista perigo iminente para os bens jurídicos aí referidos, nomeadamente por deterioração aguda do seu estado."

Para se iniciar o processo de internamento compulsivo de urgência, o MF deve contactar o delegado de saúde e, no caso de ser necessária a condução do utente ao serviço de urgência, deve ser contactada a autoridade de polícia. Em ambas as situações será útil recolher toda a informação possível, incluindo informações clínica e social, na maior parte dos casos acessíveis e conhecidas pelo MF.

Por outro lado, as autoridades de saúde e de polícia podem ordenar, oficiosamente ou a pedido (dos pais ou do representante legal do doente), a condução imediata do doente ao estabelecimento hospitalar com urgência psiquiátrica mais próximo. Este mandado de condução é comunicado de imediato pelas autoridades referidas ao Ministério Público, pois não é possível a privação de liberdade sem decisão judicial. A condução do doente a uma urgência psiquiátrica pode também ser feita sem existir esse mandado, apenas quando se verifique uma situação muito urgente e de perigo na demora. Nesse caso será lavrado um auto pelo agente policial que faz essa condução, igualmente com a comunicação imediata ao Ministério Público.

Na urgência psiquiátrica, o doente deverá ser avaliado por um médico psiquiatra e, confirmando-se a necessidade de internamento e mantendo-se a recusa do doente, o médico internará o doente para iniciar o tratamento, comunicando-o ao tribunal competente da área do hospital. Posteriormente um juiz proferirá, no prazo máximo de 48 horas, a decisão de manter ou não o internamento. Essa decisão é comunicada ao internado, ao familiar mais próximo e ao MF.

Durante o internamento deverá ser realizada dentro de 15 dias uma avaliação clínico-psiquiátrica por dois psiquiatras, sendo o relatório enviado para um juiz que designará uma data para uma sessão onde estará presente o doente e o seu defensor. Uma segunda reavaliação é obrigatória, decorridos dois meses sobre o início do internamento ou sobre a decisão que o tiver mantido.

$\mathrm{O}$ internamento termina quando estiverem resolvidas as causas que lhe deram origem, depois de alta concedida pelo director clínico do hospital ou por decisão judicial. 
O caso descrito reflecte que o MF tem vários recursos de saúde ao seu dispor, dos quais deve fazer uso de forma a melhor gerir as agudizações da doença psiquiátrica crónica. Concretamente, no caso apresentado, verifica-se como é difícil a gestão das agudizações desta doença, tendo-se recorrido ao médico psiquiatra da comunidade, aos CSS através de contactos telefónicos e referenciações ao SU hospitalar até ao último reduto, em articulação com a saúde pública.

Destaca-se ainda que o isolamento social da utente, tão típico da esquizofrenia, e a consequente ausência de elementos de referência próximos, como familiares, amigos ou vizinhos, podem ter contribuído para a manutenção e agravamento do quadro clínico. O MF, conhecedor destes elementos, tem um papel chave no acompanhamento e resolução destes episódios, podendo trabalhar em conjunto com outros recursos da comunidade: assistentes sociais, familiares e outros informantes, fazendo a articulação entre o doente, o médico psiquiatra e o médico de saúde pública. Estes elementos devem ser identificados pelo MF que pode trabalhar em conjunto com outros recursos da comunidade, como os serviços sociais, para actuar precoce e preventivamente, providenciando uma gestão integrada do doente.

\section{REFERÊNCIAS BIBLIOGRÁFICAS}

1. Perälä J. Epidemiology of psychotic disorders [Dissertation]. Helsinki: University of Helsinki; 2013. ISBN 9789522458261

2. Rodrigues E, Ribeiro H, Lessa V, Moreira D, Almeida F. Internamentos compulsivos: leis de saúde mental na Europa. Psiquiatr Psicol Justiça. 2014;(6):141-52.

3. Lei no $36 / 98$, de 24 de Julho. Diário da República. $1^{\text {a }}$ série(169).

4. Salize HJ, Dressing H. Epidemiology of involuntary placement of mentally ill people across the European Union. Br J Psychiatry. 2004;184(2): 163-8.

5. Torrey EF, Zdanowicz M. Outpatient commitment: what, why, and for whom. Psychiatr Serv. 2001;52(3):337-41.

6. Salize HJ, Dressing H, Peitz M. Compulsory admission and involuntary treatment of mentally ill patients: legislation and practice in EU-Member States (final report). Mannheim: Central Institute of Mental Health; 2002.

\section{CONFLITOS DE INTERESSES}

Os autores declaram não ter conflito de interesses.

\section{ENDEREÇO PARA CORRESPONDÊNCIA}

Unidade de Saúde Familiar Mondego

Estrada do Espírito Santo das Touregas - Quinta dos Vales

3045-059 COIMBRA

E-mail: josemendes.web@gmail.com

Recebido em 03-02-2015

Aceite para publicação em 30-08-2015

\section{ABSTRACT}

\section{SCHIZOPHRENIA:THE ROLE OF THE FAMILY DOCTOR AND THE USE OF COMPULSORY ADMISSION}

Introduction: Schizophrenia is a syndrome characterized by changes in thinking, mood and behaviour. Patients with this disorder lack insight into the disease, which often leads to non-adherence to treatment and worsening of symptoms. Compulsory admission is a last resort in these situations. Because of the difficulty in assessing these patients, close monitoring by the family doctor is required. Thus it is possible to assess the effects of the disease and permit timely initiation of psychiatric treatment.

Case description: A 48 year-old woman, divorced, unemployed, and living alone, who was diagnosed with schizophrenia at age 30, consulted her family doctor with persecutory delusions and delusional interpretations. Over a period of four months, she consulted with her family doctor for the same reasons, with a progressive deterioration in her condition. The situation evolved to a state of aggression with immediate danger to herself and others. Because she refused the necessary treatment, the health authority was contacted to arrange for compulsory admission.

Comment: Schizophrenia is a highly debilitating disease. When not under control, exacerbations in clinical status are difficult to manage. Portuguese law permits compulsory admission. The family doctor has health resources available and a privileged knowledge of the patient and the family, which can be used effectively to manage psychiatric deterioration.

Keywords: Schizophrenia; Commitment of Mentally Ill. 